\title{
Symmetrical 10Gbps Point-to-Point and Broadcast Service using Centralized Source
}

\author{
Imran Ashraf \\ Department of Telecommunication \\ Institute of Communication \\ Technologies Islamabad 44000, \\ Pakistan
}

\author{
Muhammad Idress Afridi \\ PTCL HQ Islamabad 44000, \\ Pakistan
}

\author{
Taifoor UI Islam \\ Department of Telecommunication \\ Institute of Communication \\ Technologies Islamabad 44000, \\ Pakistan
}

\begin{abstract}
In this report, the demonstration of a cost effective bidirectional WDM-PON architecture supporting symmetric data rate for both point-to-point and broadcasting services are presented. To decrease the network cost and increase the end user data rate, utilizing RZ-DPSK for point-to-point (P2P) data and intensity modulation (IM) for broadcast data in downlink direction. Single feeder fiber is used in colorless WDM PON architecture supporting both 10 Gbps point-topoint and $10 \mathrm{Gbps}$ broadcast services data. Error free transmission is achieved with low BER and eye diagrams are verified through simulation at a distance of $25 \mathrm{Km}$.
\end{abstract}

\section{Keywords}

Passive Optical Network (PON); Wavelength-division Multiplexing (WDM); Differential Phase Shift Keying (DPSK); Bit Error Rate (BER); Intensity modulation (IM); On Off Keying (OOK).

\section{INTRODUCTION}

WDM systems are trendy with telecommunication companies. Without laying new fiber it expands the capability of the network [1]. In optical communication, WDM technology carries more than one optical carrier signals on a single fiber using different wavelengths of laser light [2]. Bidirectional communication is achieved in the WDM system over one normal fiber with in increased capacity [3]. Paybacks of WDM are capacity upgrade, transparency, wavelength reuse, scalability and reliability [4].

Recently, various multimedia services like IPTV, VOD, HDTV, E-learning get more and more popular, the number of users of the service increases rapidly and each data flow which needs high bandwidth have impelled the bandwidth of access network to increase continually [5]. Therefore, the technique of access network is becoming the holdup of the growth of communication.

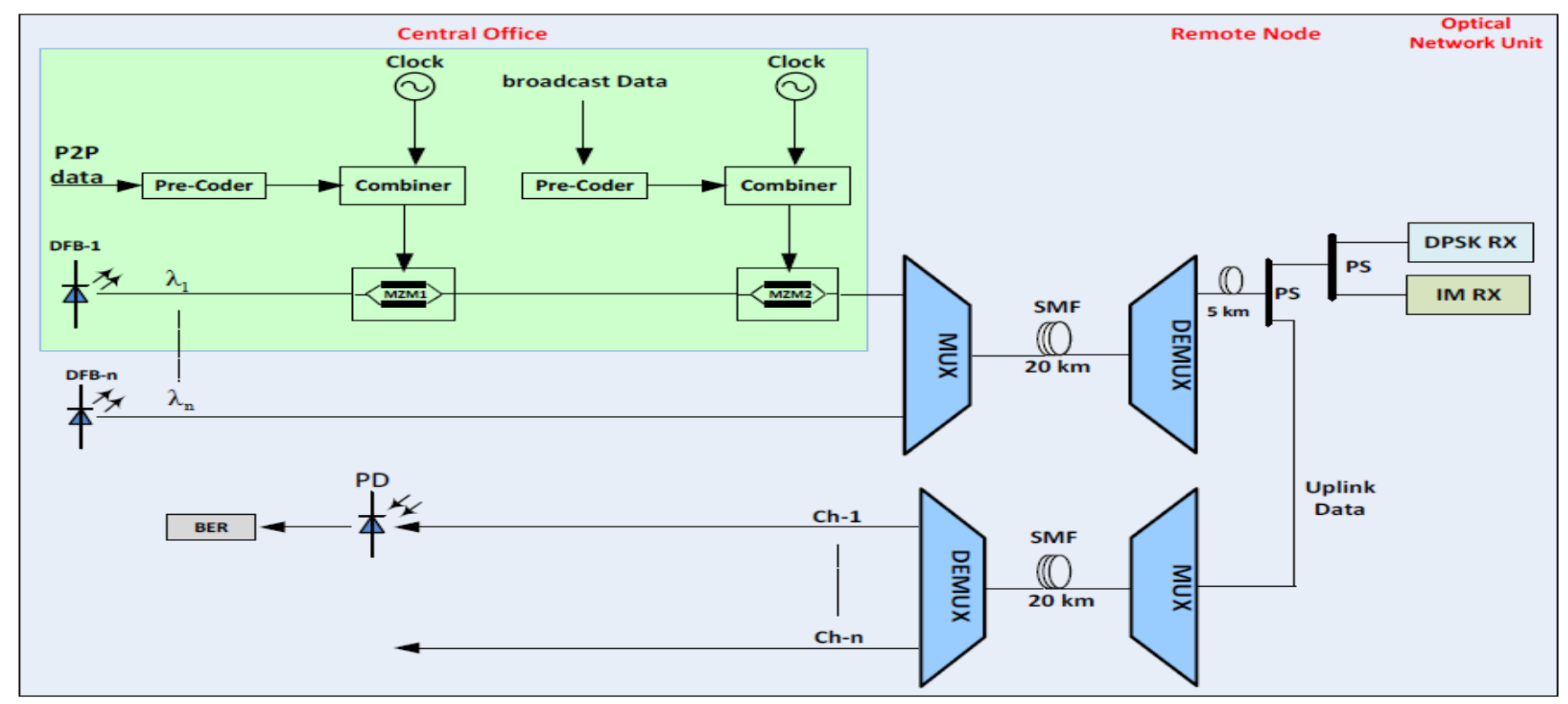

Fig 1: SchematicWDM-PON architecture for P2P and Broadcasting data 
In this paper, WDM-PON system has transmitter and receiver end. At the transmitter end numbers of signals are feeds to multiplexer which multiplexes more than one optical signal into a single fiber. At the receiver end demultiplexers are placed to split the signal to many users [6]. An optical signal is converted into electrical signal at the receiver using photo detector [7]. Then the output signal is given to many users.

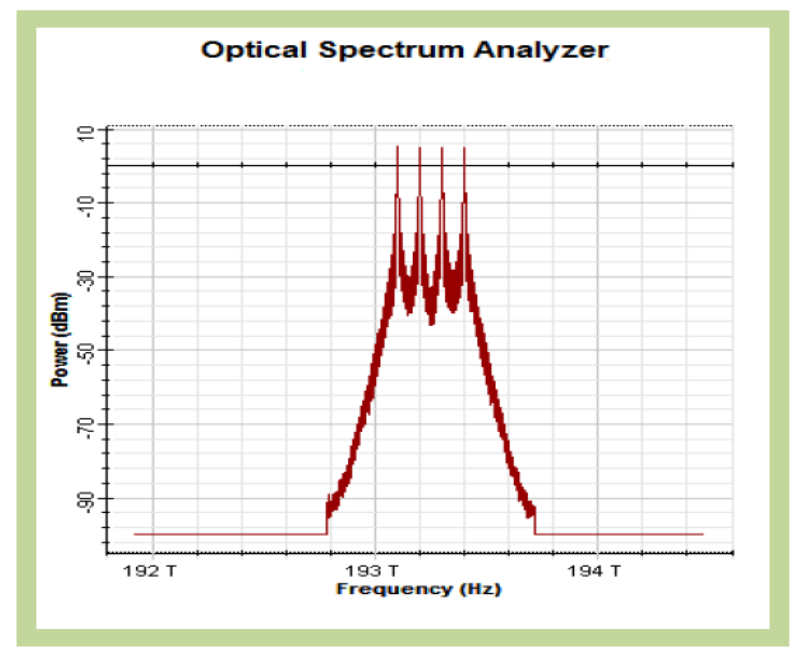

Fig 2: Four downlink multiplexed DPSK signals

\section{WORKING PRINCIPLE AND NETWORK ARCHITECTURE}

A full duplex WDM-PON network architecture is shown in Fig 1 delivering P2P and broadcast data. Base station (central office) contains four laser diodes which generates downstream wavelength from $\lambda_{1}$ to $\lambda_{4}$. When light passed through MachZender-Modulator (MZM) to achieved DPSK modulation the two complementary output $10 \mathrm{Gbps}$ precoded superimposed electrical signals clock and data which is driven by MZM [8] [9]. Other additional MZM is driven by broadcast 10Gbps data, and then both P2P and broadcast data are multiplexed. This united downstream signal is transmitted on single strand fiber over distance of $20 \mathrm{~km}$. At the access node downstream signal is demultiplexed where half power splitter is used to tape first half power for remodulation technique and fed to intensity modulator (IM) in turn to generate $10 \mathrm{Gbps}$ upstream data signal [10]. The other half power is transported through distribution fiber up to $5 \mathrm{KM}$, where signal is further by $3 \mathrm{~dB}$ power splitter at ONU. Balance-Photo-Diode and 1-bit delayed inferometer is used to demodulate the downstream DPSK signal.

Table 1: General settings

\begin{tabular}{|l|l|}
\hline Parameters & Values \\
\hline Dispersion parameter for fiber & $16.75 \mathrm{ps} / \mathrm{nm} / \mathrm{km}$ \\
\hline Dispersion slope for fiber & $0.075 \mathrm{ps} / \mathrm{nm}^{2} / \mathrm{km}$ \\
\hline Attenuation coefficient & $0.2 \mathrm{~dB} / \mathrm{km}$ \\
\hline Core area of fiber & $80 \mathrm{um}^{2}$ \\
\hline Photo dectector Responsitivity & $1 \mathrm{~A} / \mathrm{W}$ \\
\hline Dark current of photo detector & $10 \mathrm{nA}$ \\
\hline
\end{tabular}

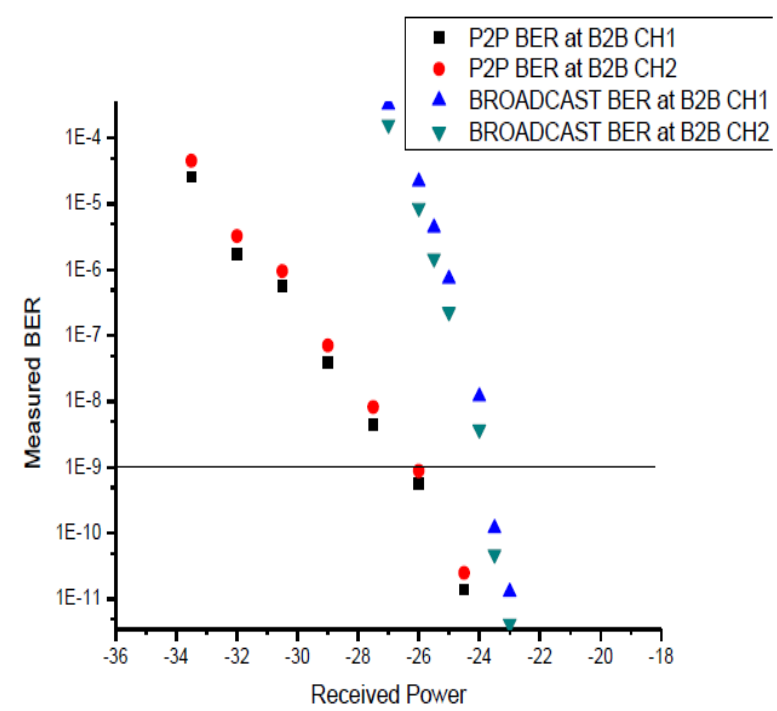

Fig 3: BER Graph for P2P and Broadcast data at B2B for Channel 1 and Channel 2

\section{SIMULATION SETUP AND OPERATION}

The proposed WDM-PON architecture for both broadcast data and point to point data was discussed and successful simulation is done by using OptiSystem 7.0 without use of pulse curve [11] shown in Figure-2. A 10Gbps bit stream of order $2^{7}$ is superimposed by $5 \mathrm{GHz}$ clock with help of combiner. First MZM modulator is used for point to point data signal very much modulate to create DPSK downstream data signal. Second MZM is intensity modulated by $10 \mathrm{Gbps}$ broadcast data. Both signals are multiplexed and transmitted over $25 \mathrm{KM}$ single feeder. A downstream signal is divided in two parts at remote node by $3 \mathrm{~dB}$ optical splitter. Intensity modulation OOK technique is used to re-modulate first half signal to generated upstream data signal. The second half signal is transmitted through $5 \mathrm{KM}$ distribution fiber. Here balance diode and MZDI is used to extract P2P data while intensity demodulator received broadcast data from received signal. General settings for proposed system are given in Table 1.

\section{PERFORMANCE ANALYSIS AND RESULTS}

Bit error rate (BER) is main criteria for performance assessment of network. Both broadcasting and P2P transmission for channel-1 and channel-2 on back to back scenario are shown in Fig 3. In downstream direction $-26 \mathrm{dBm}$ optical power is received at $10^{-9} \mathrm{BER}$ for $10 \mathrm{Gbps} \mathrm{P} 2 \mathrm{P}$ data signal, similarly $-23 \mathrm{dBm}$ power received at $10^{-9}$ BER for $10 \mathrm{Gbps}$ OOK broadcast data signal.

Fig 4 illustrate BER graph for both broadcast and P2P after transferring data over $25 \mathrm{KM}$ (20KM fiber $+5 \mathrm{KM}$ distribution fiber). In downstream direction $-24 \mathrm{dBm}$ optical power is received at $10^{-9}$ BER for $10 \mathrm{Gbps} \mathrm{P} 2 \mathrm{P}$ data signal, similarly $19 \mathrm{dBm}$ power received at $10^{-9}$ BER for $10 \mathrm{Gbps}$ OOK broadcast data signal over traversing $25 \mathrm{~km}$ fiber. Miniature power penalties for $\mathrm{P} 2 \mathrm{P}$ data $2.0 \mathrm{~dB}$ and for broadcast data $4.0 \mathrm{~dB}$ were measured during $\mathrm{B} 2 \mathrm{~B}$ scenario and after traversing $25 \mathrm{~km}$ fiber. 


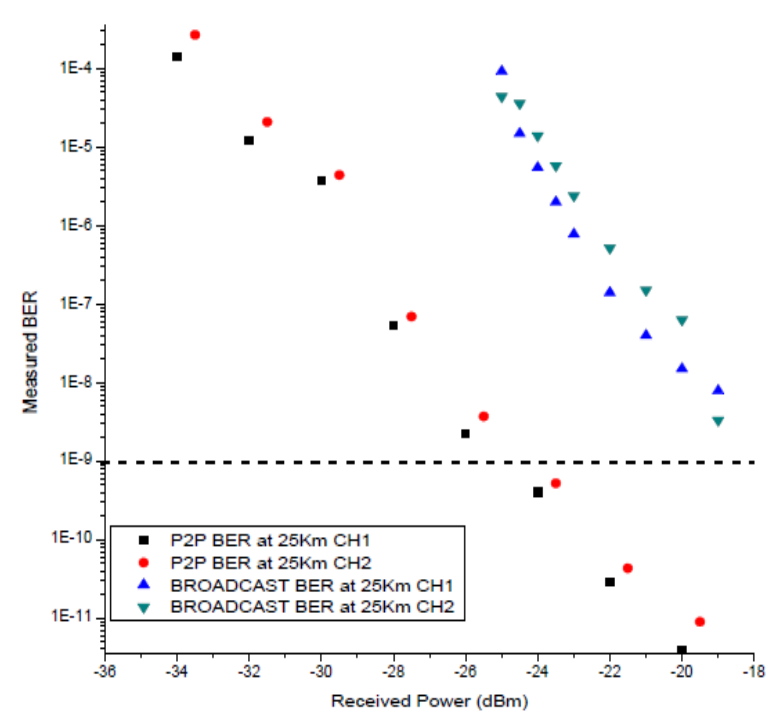

Fig 4: BER Graph for P2P and Broadcast Data at $25 \mathrm{~km}$ for Channel 1 and Channel 2

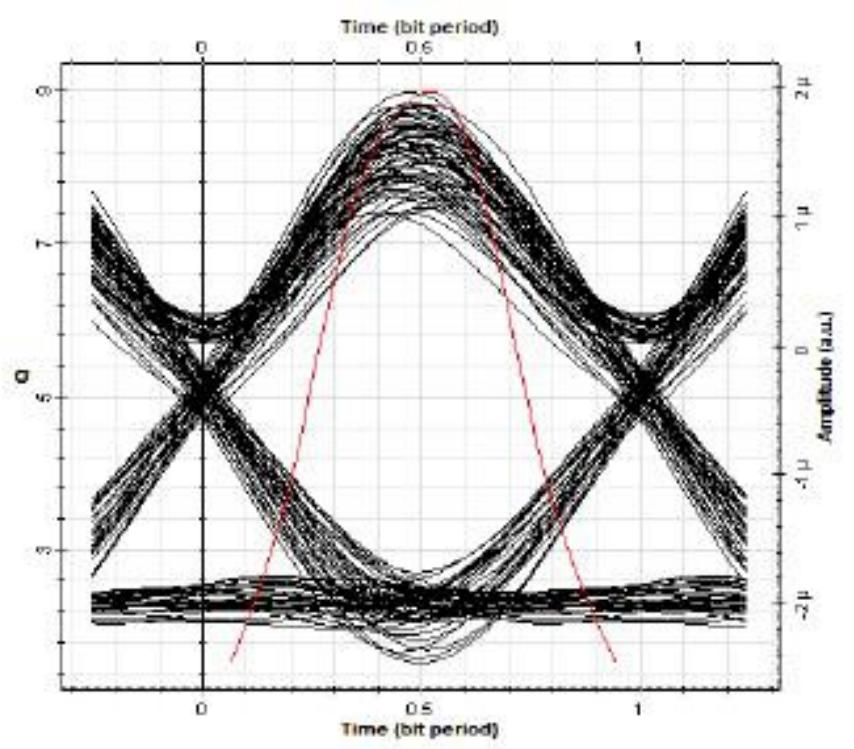

Such a miniature power penalty possibly will largely be accredited to chromatic dispersion, yet the continuous performance of the downstream signal evidently shows the applicability of such a lucrative DPSK transmitter for the implementation in upcoming WDM-PONs. Figure-5 shows the resultant optical eyes diagram for both downlink and uplink channels. These eyes are wide open and transparent.

\section{CONCLUSION}

In this paper, a lucrative WDM-PON architecture supports both broadcast and point to point services at a rate of $10 \mathrm{Gbps}$ in full duplex mode is demonstrated. Remodulate the downstream signal for uplink data by using On off Keying (OOK) technique save more resources like light source and extra modulator. Error free transmission is verified through software at a distance of $25 \mathrm{KM}$ with low BER. Low power penalties $2.0 \mathrm{~dB}$ for Point to Point and 4.0dB for Broadcast services are measured at $10^{-9} \mathrm{BER}$. Successful transmission is achieved for both downlink/uplink P2P data and broadcast service for more than on channel.

Fig 5: Eye Diagram for Point to Point and Broadcast Signals

\section{REFERENCES}

[1] J.Karunya, Dr.P.Prakash, "Analysis of WDM system using DCF", IEEE 4th International Conference on Signal Processing, Communications and Networking (ICSCN -2017), March 2017, India.

[2] R.Jirachariyakool, N.Sra-ium, S.Lerkvaranyu, "Design and Implement of GPON-FTTH network for residential condominium", IEEE 14th International Joint Conference on Computer Science and Software Engineering (JCSSE), July 2017, Thailand.

[3] S.Wang, D.Dai, "Siliconbased Reconfigurable Optical AddDrop Multiplexer For Hybrid MDMWDM Systems", Optical Fiber Communication Conference Optical Fiber
Communication Conference, March 2017, California United States.

[4] X. Xue, P. Wang, Y.Xuan, M.Qi, A. M. Weiner," HighEfficency WDM Source Based on Microresonator Kerr Frequency Combs", Optical Fiber Communication Conference Optical Fiber Communication Conference, March 2017, California United States.

[5] A. Ouali , K.F.Poon , B.S.Lee , K.Al Romaithi," Towards Achieving Practical GPON FTTH Designs", IEEE $20^{\text {th }}$ International Workshop on Computer Aided Modelling and Designe of Communication Links and Networks (CAMAD), Sept. 2015, UK.

[6] S.R.Tembo, J.L.Courant, S.Vaton, S.Gosselin, "A highly adaptable probabilistic model for self-diagnosis of 
GPON-FTTH access networks", 24th International Conference on Software, Telecommunications and Computer Networks (SoftCOM), Sept. 2016, Croatia.

[7] S.Verma, A.kakati, M.R Tripathy, A.K.ingh,S.Kumar, H.Rana, "Performance analysis of GPON network for maximum Q-FACTOR and minimum BER for various fiber length using uniform fiber Bragg's grating", International Conference on Information Technology (InCITe)- The Next Generation IT Summit on the Theme - Internet of Things: Connect your Worlds, Oct. 2016, India.

[8] T. Ul Islam, A. Husain, S.S. Arshraf, "10Gbps Bidirectional Transmission GPON Network Based on Single Fiber", IEEE International Conferences on Emerging Technologies (ICET), Dec.2015, Palistan.

[9] C.Xiong, M.Tang, C. Ke, Z.Feng, Q.Wu, L.Xu, S.Fu, W.Tong, P. P.Shum, "Experimental Demonstration of
Ultra-Dense WDM-PON With Seven-Core MCFEnabled Self-Homodyne Coherent Detection", IEEE Photonic Journal, vol. 9, no. 2, pp. 1-7, April 2017.

[10] Z.Li， Q.Dou， L.Wang, P.Yang, C.Zhou, "Simple Colorless Long-Reach WDM-PON with Rayleigh Backscattering Noise Mitigation Employing Remodulated Orthogonal Coding”, China Communications, vol. 14, no. 4, pp. 120-126, April 2017.

[11] A. Hussain, Y. Chong-xiu, X. Xiang-jun, Y. Quan-xin, L. Bo, A. Hussain, A. Latif, A. Munir, Y. Khan, and I. Afridi, "A novel duplex WDM-PON with DPSK modulated downstream and re-modulation of the downlink signal for OOK upstream", Optoelectronics Letters, vol. 8, pp. 134-137, March 2012. 